\title{
Myocardial abscess due to Salmonella typhimurium
}

\author{
Olav M. Langaker and Knut Svanes \\ From the Central Hospital of Rogaland, Dpt. Stavanger, Medical Department; The University of Bergen, \\ School of Medicine, The Gade Institute, Department of Pathology, Bergen, Norway
}

A patient with myocardial abscess due to Salmonella typhimurium is described. The cause of the abscess is
considered to be acute endocarditis with septic embolus to a coronary artery.

Myocardial abscess is a known complication of bacterial endocarditis. Gram-positive bacteria such as staphylococci, pneumococci, and streptococci are the most common pathogenic agents. None of the $\mathbf{4 2}$ cases of myocardial abscess discussed by TschudiMadsen (I960) was caused by Gram-negative bacteria. Lerner and Weinstein (I966) reported five cases, one caused by Salmonella (enteritides).

The present report concerns a patient with myocardial abscess caused by Salmonella typhimurium, which does not appear to have been previously described apart from one brief notice (Hurst and Logue, 1970).

The abscess was in the atrial septum and was accompanied by complete AV dissociation. Only one case of myocardial abscess in this site and with this conduction disturbance appears to have been previously reported (Zettner and Irmiere, 1959).

\section{Case report}

A 76-year-old man, had resection of the stomach in 1939. There was no previous history of rheumatic fever or heart disease.

In August 1969, the patient became ill with lassitude, vertigo, and profuse diarrhoea. He was admitted to hospital (University Hospital of Bergen) four days later; he was thin, dehydrated, and mentally confused, but had no fever. The blood pressure was $125 / 70 \mathrm{mmHg}$ with a regular pulse $96 / \mathrm{min}$. The apex beat was not palpable. A short, high pitched systolic murmur, and a soft diastolic decrescendo murmur were heard over the base of the heart. The aortic second sound was present.

During the following days the patient was in a serious fluid electrolyte condition with diarrhoea and fluid electrolyte disturbances. Bacteriological examination of faeces showed Salmonella typhimurium. After one week the diarrhoea ceased, but culture of faeces continued to grow Salm. typhimurium until the middle of September. On 18, 19, and 21 August and 4 September the patient had rigors and rising temperature. Blood cultures showed growth of Salm. typhimurium.
Antibiotic treatment was started with ampicillin at the time of the first attack of rigor. When rigor again set in, this was replaced by chloramphenicol. Later ampicillin was given again, and finally pivampicillin. The blood culture became negative, but the temperature remained slightly raised.

The diagnosis of subacute bacterial endocarditis was considered.

After correction of fluid and electrolyte abnormalities the patient showed slight anaemia and a leucopenia of $4000 / \mathrm{mm}^{3}$, which later changed to a leucocytosis of $18,000 / \mathrm{mm}^{3}$. The bone marrow was found to be normal. The sedimentation rates were 24,75 , and $57 \mathrm{~mm}$ (Westergren). Creatinine normal. Serum iron fell from $74 \mu \mathrm{g} / \mathrm{I} 00 \mathrm{ml}$ to $30 \mu \mathrm{g} / \mathrm{I} 00 \mathrm{ml}$. Liver function tests were normal. On admission Widal was negative, later positive $\mathrm{I}: 1000$. An electrocardiogram on admission in August showed normal sinus rhythm, but later, on 20 September, it showed negative $T$ waves in all praecordial leads, suggesting subendocardial infarction. $X$-ray of the chest showed a basal infiltration; the heart shadow was normal.

During the stay in hospital and on discharge at the end of October, the patient remained ill with normal temperatures. He went to stay with relatives in another town, and there his symptoms of sepsis recurred. He received a 3-day course of doxycycline chloride, resulting in fall in temperature and slight improvement of his condition. However, on the third day (8 November), he became suddenly ill again with rigors, loss of consciousness, and irregular respiration.

On admission to the Central Hospital of Rogaland he was in coma, with Cheyne-Stokes respiration, temperature $39.6^{\circ} \mathrm{C}$, blood pressure $115 / 65 \mathrm{mmHg}$, and irregular pulse of 135 a minute. Cardiac examination showed no pulse deficit, and no murmurs could now be heard. Electrocardiogram showed atrial fibrillation with tachycardia and the patient was given digoxin $0.50 \mathrm{mg}$ daily. Haemoglobin was 80 per cent, sedimentation rate 96 $\mathrm{mm} / \mathrm{hr}$; electrolytes were normal. Widal was positive I:20,480. He had two rigors, and blood cultures again showed Salmonella typhimurium. Stool cultures were negative.

In spite of treatment with antibiotics the patient's 


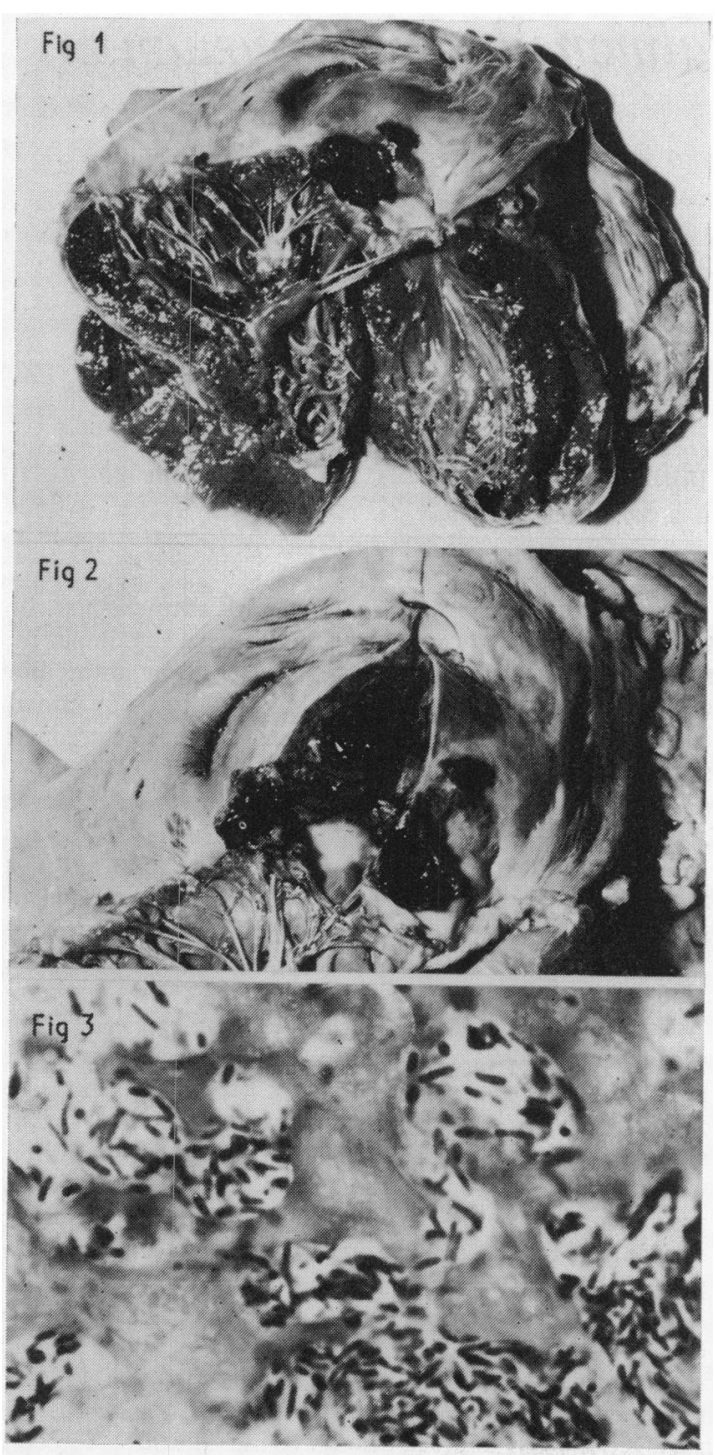

FIG. I Polypoid vegetation attached to the proximal aspect of the anterior cusp of the mitral valve and to the adjacent part of the atrial septum. Heart of 76year-old man with Salmonella typhimurium infection.

FIG. 2 Same heart as in Fig. I. Section laid through the vegetation into the atrial septum. The figure shows a large abscess cavity in the atrial septum just inside the attachment of the vegetation.

FIG. 3 Section of the vegetation shown in Fig. I. The figure shows thrombus masses with abundant rodshaped bacteria. (Haematoxylin and eosin. $\times 1500$.) condition deteriorated. On I8 November, the electrocardiogram showed probable complete AV dissociation with nodal rhythm. His temperature rose again during the next few days, and on 26 November he died suddenly.

\section{Necropsy}

The heart weighed $380 \mathrm{~g}$. The pericardial sac contained $200 \mathrm{ml}$ haemorrhagic fluid. The pericardium was covered with a thin layer of fibrin. A friable polypoid vegetation was attached to the proximal aspect of the anterior cusp of the mitral valve and to the adjacent part of the atrial septum (Fig. I). A section through the vegetation into the atrial septum disclosed a cavity measuring about $2.5 \times 2.5 \times 1.5 \mathrm{~cm}$ containing blood and pus (Fig. 2). The abscess was located between the aorta ascendens and the left atrium and within the anterior part of the atrial septum. The remaining part of the septum showed pronounced swelling. A calcified nodule, diameter 2 to $3 \mathrm{~mm}$, was found at the attachment of the posterior mitral valve. The myocardium appeared normal. In the coronary arteries there was considerable atherosclerosis, but no occlusion.

Microscopical examination The pericardium was infiltrated with lymphocytes and large macrophages, and the surface was partly covered with a thin layer of fibrin. The vegetation in the left atrium was composed of clotted blood and thrombus masses with abundant Gram-negative rod-shaped bacteria centrally (Fig. 3). The abscess cavity contained erythrocytes, neutrophils, and macrophages. The wall of the abscess was infiltrated with numerous neutrophils and macrophages and some lymphocytes and plasma cells. Inflammatory cells were present in the intima and adventitia of the ascending aorta adjacent to the abscess, and in the right and left cusps of the aortic valve. Sections of the left ventricle and the muscular part of the interventricular septum showed numerous small arteries occluded with thrombi. In a couple of these vessels the walls were infiltrated with inflammatory cells. Numerous microinfarcts composed of necrotic muscle fibres and loose connective tissue with some pigment macrophages were seen in the myocardium.

Bacteriological examination of blood, pus from the cardiac abscess, bile from the gall bladder, intestinal content, and material from spleen and lungs showed growth of Salmonella typhimurium from the blood and pus, but not from the remaining samples.

\section{Discussion}

In 2000 cases of salmonellosis in New York 196566 , septicaemia was present in 4.8 per cent. Half of these were due to Salmonella typhimurium. Of the 24 cases developing an abscess, 4 grew the organism on culture (Cherubin et al., 1969). In spite of the few reports on myocardial abscess, some authors believe the condition to be more frequent 
than reported (Sheldon and Golden, 195I). Applying a meticulous dissection technique, they showed abscess of the valve rings in 12 of 14 cases of acute bacterial endocarditis. In cases of subacute endocarditis myocardial lesions were found in 19 of 20 hearts (De Navasquez, 1939). This indicates that small abscesses are easily overlooked.

The pathogenesis is still debatable. In our case the microscopical findings of numerous microinfarcts and small arteries occluded with thrombi, partly with evidence of inflammation, make infected emboli the most probable cause of the abscess. The signs of subendocardial infarction on 20 September support this theory. However, a per continuitatem extension cannot be excluded.

\section{References}

Cherubin, C. E., Fodor, T., Denmark, L. I., Master, C. S., Fuerst, H. T., and Winter, J. W. (1969). Symptoms, septicemia and death in salmonellosis. American fournal of Epidemiology, 90, 285.

de Navasquez, S. (1939). The incidence and pathogenesis of myocardial lesions in subacute bacterial endocarditis. fournal of Pathology and Bacteriology, 49, 33.

Hurst, J. W., and Logue, R. B. (1970). The Heart, 2nd ed., p. I 197. McGraw-Hill, New York.

Lerner, P. I., and Weinstein, L. (I966). Infective endocarditis in the antibiotic era. New England fournal of Medicine, 274, 388.

Sheldon, W. H., and Golden, A. (I95I). Abscesses of the valve rings of the heart, a frequent but not well recognized complication of acute bacterial endocarditis. Circulation, $4, \mathrm{I}$.

Tschudi-Madsen, S. (1960). Abscesses in the heart. Nordisk Medicin, 63, 429.

Zettner, A., and Irmiere, V. J. (1959). Abscess of the heart. A complication of acute vegetative and ulcerative endocarditis. Circulation, 20, 590.

Requests for reprints to Dr. Olav M. Langaker, Sentralsjukehuset i Rogaland, avd. Rogaland sjukehus, med. avd., 4000 Stavanger, Norway. 